\title{
Preliminary investigations of antioxidation of dihydromyricetin in polymers
}

\author{
QIUKAI ZHENG ${ }^{\dagger}$, LINLI XU XINHUA ZHU $^{\dagger}$, JIA CHEN ${ }^{\dagger}$, FEIYUE LIU ${ }^{\dagger}$, \\ DEHONG CHEN ${ }^{\dagger}$, KAI XU and MINGCAI CHEN* \\ Guangzhou Institute of Chemistry, Chinese Academy of Sciences, Guangzhou 510650, P.R. China \\ ${ }^{\dagger}$ Graduate School of Chinese Academy of Sciences, Beijing 100039, P.R. China
}

MS received 17 December 2008; revised 18 January 2009

\begin{abstract}
The antioxidative properties of dihydromyricetin (DMY), extracted from Ampelopsis grossedentata, in different solid polymers were evaluated by measuring the oxidation induction temperature (OIT*). The antioxidative efficiency was compared with Irganox 1010. The results showed that DMY was more efficient than the synthetical antioxidant. The high antioxidant activity of DMY is attributed to the special chemical structure, including the quantity and positions of the hydroxy groups in the molecule. DMY was harmless and highly effective to be a good natural antioxidant.
\end{abstract}

Keywords. Polymers; corrosion and oxidation; natural antioxidant; dihydromyricetin.

\section{Introduction}

Flavonoids account for over half of the 8,000 naturally occurring phenolic compounds (Harborne et al 1999), constituting the largest group of plant phenolics that are of considerable physiological importance in growth and reproduction, providing protection against pathogens and predators in plants (Bravo 1998). The beneficial effects derived from phenolic compounds have been attributed to their antioxidant activity (Heim et al 2002).

Ampelopsis grossedentata $\mathrm{W} \mathrm{T}$ Wang, distributed in South China widely, has been used as a beverage for thousands of years. 3,3', 4',5,5',7-hexahydroxy-2,3-dihydroflavanol (DMY), the main bioactive component in the stems and leaves of Ampelopsis grossedentata, is one kind of flavonoids which has many pharmacological functions on organism, such as relieving cough, removing sputum, inhibiting hypertension, protecting liver (Yabe and Matsui 1997; Yabe et al 1998; Murakami et al 2004), absorbing ultraviolet radiation (Towatari et al 2002; Anu et al 2003; Riitta et al 2003), antioxidation (Zhang et al 2003; Ma et al 2003, 2004), antibacterial properties (Matsumoto and Tahara 2001; Liu et al 2004; Hayashi et al 2005). However, there is no information about the antioxidative properties of DMY in polymer. This paper describes the functions of DMY on these aspects.

\footnotetext{
*Author for correspondence (mcchen@gic.ac.cn)
}

\section{Experimental}

Dried tender stems and leaves of Ampelopsis grossedentata were mixed with ethanol and were continuously extracted for $1 \mathrm{~h}$ at reflux conditions. The collected extract was evaporated at $40^{\circ} \mathrm{C}$ under reduced pressure. Recrystallizations were carried out 5 times in water to purify DMY based on different solubility in boiled water and cold water. The purity of DMY was $97.3 \%$ analysed by HPLC (Prep Nova-Pak HR C18 column $3.9 \times$ $300 \mathrm{~mm}$, Waters Co., USA). The mobile phase was acetonitrile-water-acetic acid $(1: 9: 0 \cdot 1)$. The flow rate was $1 \mathrm{ml} / \mathrm{min}$. The effluent was monitored at $288 \mathrm{~nm}$ and the injection volume was $20 \mu \mathrm{l}$.

Thermal stability of DMY was measured by PerkinElmer Diamond differential scanning calorimeter (DSC) and Pyris 1 thermogravimetric analysis (TGA). The sample of purified DMY was scanned from $50-300^{\circ} \mathrm{C}$ at the rate of $10^{\circ} \mathrm{C} / \mathrm{min}$.

DMY and Irganox 1010 dissolved in trichloromethane was poured into a beaker containing polymer powder. The solvent was removed through evaporation. Doubleroll blending machine was used for blending polymers with antioxidants. The mixed powders were compressed into films, $0.5 \mathrm{~mm}$ thick. The machining temperatures were $180^{\circ} \mathrm{C}$ for polypropylene (PP, XD-045, Yueyangxingchang Petrochemical Co., Ltd), $120^{\circ} \mathrm{C}$ for linear low density polyethylene (LLDPE, DFDA-2001, China Petrochemical Co., Ltd), $130^{\circ} \mathrm{C}$ for high density polyethylene (HDPE, 2911, China Petrochemical Co., Ltd), $185^{\circ} \mathrm{C}$ for polystyrene (PS, raw material, Kingfa Sci. \& Tech. Co., $\mathrm{Ltd}), 25^{\circ} \mathrm{C}$ for ethylenevinyl acetate copolymer (EVA, 
260, Mitsui Polychemical Co., Ltd), natural rubber (NR, Viet Nam 3L) and nitrile butadiene rubber (NBR, Taiwan NANCAR 4155), respectively. The weight ratios of antioxidants were $0.2 \%, 0.4 \%, 0.6 \%$ and $0.8 \%$ for PP. All the other polymer samples contained $0.4 \mathrm{wt} \%$ of DMY. Also, pure polymer samples were prepared at relevant schedules.

Thermooxidative stability of the samples was evaluated by DSC. Non-isothermal conditions were chosen to estimate the effectiveness of antioxidants in polymer plaques. OIT* is determined as the point in the thermogram where the onset of the decomposition signal results. The oxidation was observed as an increase in heat flow. The samples of 5-8 $\mathrm{mg}$ were placed in perforated aluminum pans with an oxygen flow of $20 \mathrm{ml} / \mathrm{min}$. Heating rates were $10^{\circ} \mathrm{C} / \mathrm{min}$.

\section{Results and discussion}

The DSC curve of DMY showed that an endothermic peak appeared at about $247 \cdot 8^{\circ} \mathrm{C}$ (the melting point) followed closely by an exothermic peak, while mass loss occurred at the same temperature in TGA curve (figure 1), which means the processes of melting and oxidative decomposition might occur simultaneously. It can be seen that DMY shows a good thermal stability below $230^{\circ} \mathrm{C}$, which could, therefore, be used on the polymers whose processing temperatures are lower than $230^{\circ} \mathrm{C}$.

From the non-isothermal DSC measurements, the values of OIT* for non-stabilized PP and PP stabilized by natural antioxidant DMY and synthesized antioxidant Irganox 1010 in various concentrations are plotted in figure 2. These two kinds of antioxidants both increased

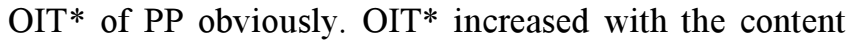
of antioxidants when the additive content of antioxidants was between 0 and $0 \cdot 8 \%$. As shown in figure 2, PP containing DMY had a higher OIT*-value than Irganox 1010

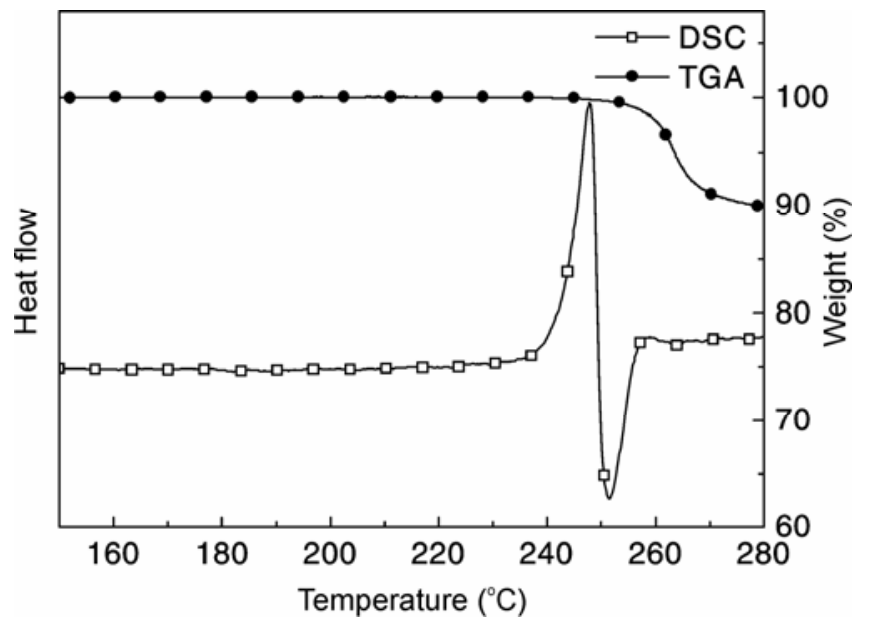

Figure 1. The DSC and TGA curves of DMY. at the same content, which implies that DMY exhibits greater efficiency than Irganox 1010 as a thermal antioxidant for PP.

The antioxidative properties of DMY in other polymers were tested as well. The onset temperatures are plotted in figure 3 . Although the concentrations of the antioxidants were equivalent, the overall performances in different solid polymers exhibited considerable differences. DMY increased OIT* of all these polymers at this concentration. Minimum performance of DMY was reached on NR for just $8^{\circ} \mathrm{C}$ increase, while the maximum one appeared on LLDPE for over $60^{\circ} \mathrm{C}$, as compared with unstabilized references.

The antioxidant activity of DMY is due to the ability to scavenge free radicals, donate hydrogen atoms or electron, and chelate metal cations. Investigations indicated that most of the flavonoids existing in various plants possess antioxidative function. The structure of flavonoid

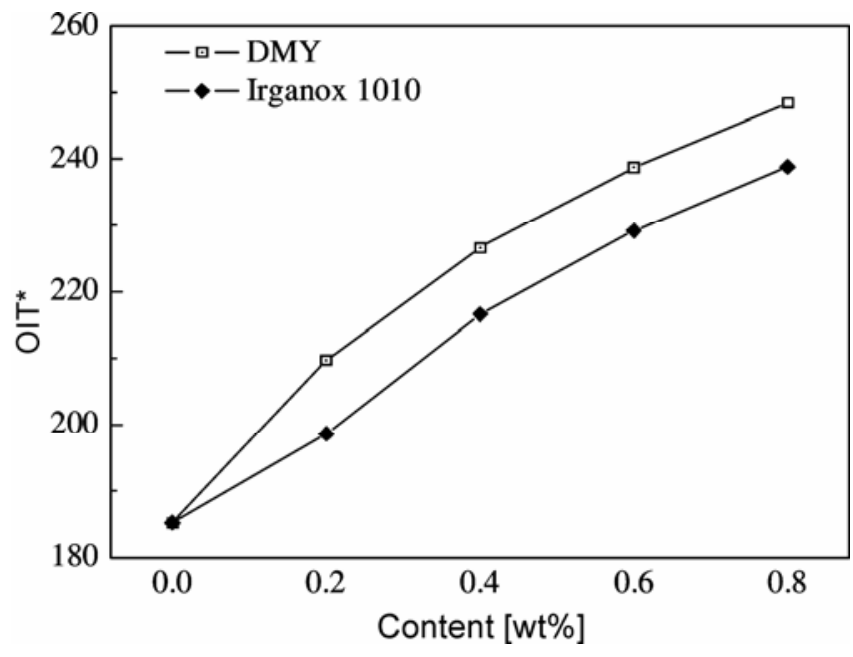

Figure 2. OIT* of PP stabilized with DMY and Irganox 1010 in various concentrations.

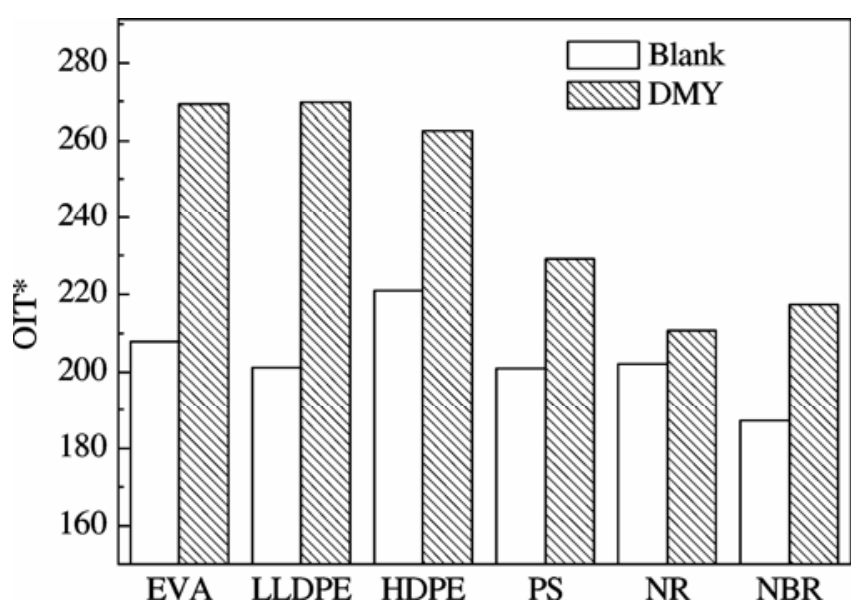

Figure 3. OIT* of non-stabilized and stabilized polymers at $0.4 \mathrm{wt} \%$ of DMY. 
<smiles>C[C@H]1Oc2cc(O)cc(O)c2C(=O)[C@H](O)C1c1cc(O)c(O)c(O)c1</smiles>

Figure 4. Chemical structure of dihydromyricetin.

compounds is a key determinant of their radical scavenging and metal chelating activity, and this is referred to as structure-activity relationships (Balasundram et al 2006). The main group participating in the reaction is hydroxy group which supplies hydrogen atom to terminate the active free radical and generates stable free radicals to prevent the chain from growth. DMY consists of fifteen carbon atoms, arranged in a $\mathrm{C} 6-\mathrm{C} 3-\mathrm{C} 6$ configuration, and possesses six hydroxy groups (figure 4 ). The nature of substitutions on ring $B$ has great influence on the antioxidant activity. $3^{\prime}, 4^{\prime}, 5^{\prime}$-trihydroxylphenyl of the ring in DMY results in higher activity compared to those that have a single hydroxyl group. The ortho-phenolic hydroxy groups are important for scavenging anion free radicals as they confer higher stability to the radical by electron delocalization, and act as the preferred binding site for trace metals (Pietta 2000). Besides, the presence of hydroxyl groups at the 3-position of the ring $\mathrm{C}$ and 5-, 7-positions of the ring $\mathrm{A}$ also enhances the active radical scavenging capacity. In general, the special chemical structure of DMY is the reason for the high antioxidant activity.

\section{Conclusions}

Thermooxidative stability of PP, LLDPE, HDPE, PS, EVA, NR and NBR stabilized by DMY has been investigated preliminarily. DMY is a more efficient thermal antioxidant for polymers compared to Irganox 1010 . The content of DMY is more than $27 \%$ in the tender stem and leaves of Ampelopsis grossedentata (Zhang et al 2001), which could, therefore, be a natural source of antioxidants. DMY has the character of good stability, high activity and abundant resources to be a good natural antioxidant.

\section{References}

Anu L, Pedro A J, Markku L and Riitta J T 2003 Environ. Exp. Bot. 4949

Balasundram N, Sundram K and Samman S 2006 Food Chem. 99191

Bravo L 1998 Nutr. Rev. 56317

Harborne J B, Baxter H and Moss G P 1999 Phytochemical dictionary: Handbook of bioactive compounds from plants (London: Taylor \& Francis), 2nd edn

Hayashi T, Tahara S and Ohgushi T 2005 Biochem. Syst. Ecol. 3327

Heim K E, Tagliaferro A R and Bobilya D J 2002 J. Nutr. Biochem. 13572

Liu D Y, Ye J T, Yang W H, Yan J, Zeng C H and Zeng S 2004 Biomed. Environ. Sci. 17153

Ma J, Luo X D, Protiva P, Yang H, Ma C Y and Basile M J 2003 J. Nat. Prod. 66983

Ma J, Yang H, Basile M J and Kennelly E J 2004 J. Agric. Food. Chem. 195873

Matsumoto T and Tahara S 2001 Nippon. Nogeik. Kaishi. 6659

Murakami T, Miyakoshi M, Araho D, Mizutani K, Kambara T and Ikeda T 2004 Biofactors 2117

Pietta P G 2000 J. Nat. Prod. 631035

Riitta T, Timo V, Pedro J A and Riitta J T 2003 Basic Appl. Ecol. 4219

Towatari K, Yoshida K, Mori N, Shimizu K, Kondo R and Sakai K 2002 Planta. Med. 68995

Yabe N and Matsui H 1997 J. Ethnopharmacol. 5631

Yabe N, Tanaka K and Matsui H 1998 J. Ethnopharmacol. 59 147

Zhang Y S, Yiang W L and Xi H P 2001 J. Hunan. Agric. Univ. 27100

Zhang Y S, Ning Z X, Yang S Z and Wu H 2003 Acta Pharmac. Sin. 38241 